\title{
Case Selection and Supreme Court Pivots
}

\author{
Greg Sasso* $\quad$ Gleason Judd ${ }^{\dagger}$
}

October 10, 2020

\begin{abstract}
How does the Rule of Four affect Supreme Court decisions? We show two effects of changing a "hearing pivot" justice who is decisive for case selection. First, a court with more extreme hearing pivots will hear cases with more moderate precedents. For example, as the conservative hearing pivot becomes more extreme, the court hears a broader range of cases with liberal status quo precedents. Second, more extreme hearing pivots shrink dispositional majorities and lead to more polarized rulings. If the median justice becomes more extreme without changing the hearing pivots, then rulings are more extreme. The effect on the range of cases heard, however, is smaller than that from changing hearing pivots. Finally, we show that case selection can also depend on non-median, non-hearing-pivot justices. Replacing an extreme justice with someone even more extreme can lead to a smaller set of heard cases, as final rulings can shift away from the binding hearing pivot, making status quo precedents more appealing.
\end{abstract}

Word Count: 3925

*Emory University, gregory.sasso@emory.edu

†Princeton University, gleason.judd@ princeton.edu 


\section{Introduction}

Many Supreme Court appointments have not changed the median Supreme Court justice. Recent examples are the appointments of Justices Sotomayor, Kagan, and Gorsuch. Yet, observers widely view policy outcomes as changing only when the median justice changes. ${ }^{1}$

We analyze a formal model to explore the consequences of changing the Supreme Court's composition without necessarily changing the median justice. Does the court's composition change which cases are heard? If so, how? Do policy outcomes change when non-median justices change?

Our model reflects three key features of the Supreme Court. First, granting certiorari requires approval by only four justices (colloquially known as the Rule of Four). Thus, changing the fourth-most liberal or fourth-most conservative justice shifts the pivotal voter for case selection. Second, majority opinions are created collectively. Therefore the court's composition can also change the output of the opinion-writing process (Lax and Cameron (2007), Carrubba et al. (2012), Cameron and Kornhauser (2010), Parameswaran, Cameron and Kornhauser (2019)). Third, dispositional votes determine who can influence the majority opinion. For any heard case, justices first decide whether to overturn or uphold the current ruling. These dispositional votes then determine which direction precedent will shift, as the bargaining coalition only includes justices supporting the majority disposition.

We build on existing models of the Supreme Court by adding a first stage where justices decide whether to grant certiorari. And for the final majority opinion, we use a reduced form approach reflecting properties of judicial bargaining models like Carrubba et al. (2012) and Lax and Cameron (2007).

We show two effects of changing justices who are pivotal for case selection. First, as hearing pivots become more extreme, the court is willing to hear cases with more moderate precedents. For example, the court hears a broader range of cases with relatively liberal precedents as the conservative hearing pivot becomes more extreme. We do not interpret this result as the court hearing

\footnotetext{
${ }^{1}$ See Roeder (2018) and Buchanan and Yourish (2018) for conventional wisdom upon Justice Kennedy's retirement, as well as Moraski and Shipan (1999) and Krehbiel (2007) for theoretical grounding.
} 
a greater number cases because, empirically, case loads have been relatively constant for the past twenty years, at about seventy to eighty cases per term. Instead, we interpret it as the court being more permissive in the nature of cases it hears.

Second, more extreme hearing pivots lead to more split decisions. Intuitively, in more moderate cases, there is less consensus about which direction to move policy. Thus, dispositional votes are more divisive when those cases are granted certiorari.

We then study the effects of replacing the median justice. When the median becomes more extreme and hearing pivots remain constant, observed rulings of heard cases become more extreme as the majority opinion shifts. Yet, the range of heard cases changes less than when hearing pivots become more extreme. If, however, the old median's replacement is more extreme than a previous hearing pivot, then that previous pivot becomes the new median and the new justice becomes a hearing pivot. The court hears more moderate cases and these cases result in more extreme rulings.

Next, we show how case selection depends on non-pivotal, non median justices. Replacing an extreme justice with someone even more extreme can shrink the set of cases heard: extreme justices may pull rulings away from the binding hearing pivot, making status quo precedent more appealing. Finally, we conclude with a discussion of the consequences of the death of justice Ruth Bader Ginsberg and court packing. Overall, our analysis emphasizes that case selection depends on strategic behavior by justices (Kastellec and Lax, 2008; Johnson, 2018; Bonica, Chilton and Sen, 2020) and our departure from canonical move-the-median games (Cameron and Kastellec, 2016) provides new implications of Supreme Court composition.

To our knowledge, the only models studying the Rule of Four are Lax (2003) and Fang, Johnson and Roberts (2007). In settings different from ours, Lax shows how the Rule of Four can increase lower court compliance with Supreme Court decisions, while Fang, et al. focus on how the minority can use the Rule of Four to its advantage.

Models of case selection typically assume the court receives a flow of possible cases (Beim, 2017; Clark and Kastellec, 2013; Parameswaran, 2018; Callander and Clark, 2017; Fox and Vanberg, 2014) and tries to rule correctly despite informational problems. We ignore informational 
problems and focus on ideology. Our focus allows us to isolate ideology, and we view our approach as complementing work analyzing informational considerations. ${ }^{2}$

\section{Model Basics}

We study a spatial policy-making game. The players are $n$ (odd) justices. There is a case with status quo $x_{s q}$ in policy space $\mathbb{R}$. In our judicial context, policy is best thought of as a threshold. For example, what is an acceptable level of force by police? Moving policy leftward corresponds to a lower level of acceptable police force.

Timing. In the first stage, justices collectively decide whether to hear the case. To capture minority quotas such as the Rule of Four, hearings require consent from $m=\frac{n-1}{2}$ justices. Hearings impose costs $c \geq 0$ on each justice. ${ }^{3}$

If the case is not heard, the game ends with $x_{s q}$ persisting.

Otherwise, there is a dispositional vote decided by majority rule. Each justice votes whether to move policy left or right from $x_{s q} \cdot{ }^{4}$ We denote rightward votes $d=1$ and leftward votes as $d=0$. After the dispositional vote, justices in the dispositional majority determine the new policy location, which we refer to as the final ruling. ${ }^{5}$

Preferences. Policy preferences are represented by quadratic loss utility. ${ }^{6}$ Thus, each justice $i$ has ideal point $\hat{x}_{i} \in \mathbb{R}$. Without loss of generality, we order justices $\hat{x}_{1}<\hat{x}_{2}<\cdots<\hat{x}_{n}$.

Along with the final ruling's location, justices care about dispositional votes. ${ }^{7}$ One might wonder why justices ever vote against the majority; joining allows them to participate in bargaining and possibly influence the final outcome. In practice, however, dissenting may signal future behavior (Ginsburg, 2010) or increase a case's media coverage (Bryan and Ringsmuth, 2016). Moreover,

\footnotetext{
${ }^{2}$ For more comprehensive surveys of the literature, see Cameron and Kornhauser (2017), and Kastellec (2017).

${ }^{3} \mathrm{We}$ interpret this cost as specific to the case under consideration. For example, hearing a case earlier in the term may be costlier than hearing a later case if the opportunity cost of deciding which cases to hear decreases as the term progresses. However, the incentives in our analysis apply broadly.

${ }^{4}$ In the U.S. Supreme Court, dispositional votes are whether to uphold or overturn. But in practice, written opinions move policy regardless of whether the specific case is upheld or overturned.

${ }^{5}$ We ignore the possibility of concurring opinions in the model. They do not affect the results.

${ }^{6}$ All results hold if policy utilities are represented by a loss function $l\left(x-\hat{x}_{i}\right)$ that is concave and single-peaked at 0 .

${ }^{7}$ Carrubba et al. (2012), Cameron and Kornhauser (2010), and Cameron and Kornhauser (2017) provide detailed justification for modeling dispositional motivations.
} 
justices may care about reputation, which could be damaged by joining dispositions they oppose.

Dispositional motivations are represented by $I \cdot 0+(1-I) \cdot l\left(x_{s q}-\hat{x}_{i}\right)$; where $I=1$ if justice $i$ joins her preferred disposition and $I=0$ otherwise, and $l()$ is a concave loss function single peaked at 0 . Voting against dispositional motivation is costlier for justices farther from the status quo. ${ }^{8}$

Justice $i$ 's payoff from not hearing the case is $-\left(x_{s q}-\hat{x}_{i}\right)^{2}$. Because each justice $i$ incurs costs $c$ from a hearing, $i$ 's payoff from hearing a case resulting in final ruling $x^{*}$ is $U_{i}\left(x^{*}\right)-c$, where

$$
U_{i}\left(x^{*}\right)= \begin{cases}-\left(x^{*}-\hat{x}_{i}\right)^{2} & \text { if vote for preferred disposition } \\ -\left(x^{*}-\hat{x}_{i}\right)^{2}+l\left(x_{s q}-\hat{x}_{i}\right) & \text { if vote against preferred disposition. }\end{cases}
$$

\section{Final Rulings}

In practice, final rulings likely result from bargaining among majority justices. We do not explicitly model such bargaining. Instead, we assume final rulings satisfy four properties. Let dispositional majority $M$ have associated final ruling $x_{M}^{*}$.

\section{Properties of final rulings:}

1. If justice $i$ is in dispositional majority $M$, then $0 \leq \frac{\partial x_{M}^{*}}{\partial \hat{x}_{i}} \leq 1$.

2. If justice $j$ satisfies $\hat{x}_{j} \geq x_{M_{1}}^{*}$ for dispositional majority $M_{1}$ and $M_{2}=M_{1} \cup j$, then $x_{M_{2}}^{*} \geq x_{M_{1}}^{*}$. Symmetrically, $\hat{x}_{j} \leq x_{M_{1}}^{*}$ implies $x_{M_{2}}^{*} \leq x_{M_{1}}^{*}$.

3. Let $\overline{\hat{x}}_{M}$ denote the rightmost justice in dispositional majority $M$ and $\hat{\underline{x}}_{M}$ denote the leftmost. Then $x_{M}^{*} \in\left[\underline{\hat{x}}_{M}, \overline{\hat{x}}_{M}\right]$.

4. Let justice $i$ be in dispositional majorities $M_{1}$ and $M_{2}$, where $M_{1} \subset M_{2}$. Then $\frac{\partial x_{M_{1}}^{*}}{\partial \hat{x}_{i}} \geq \frac{\partial x_{M_{2}}^{*}}{\partial \hat{x}_{i}}$.

Broadly, the properties say that all justices in the dispositional majority can (weakly) affect final rulings. By Property 1, shifting a dispositional majority justice moves final rulings weakly in that same direction. Property 1 also limits the size of that shift. Property 2 implies that adding a

\footnotetext{
${ }^{8}$ In our context, this captures the spirit of the observation that "making a mistake on what should be a 'slam dunk' case is more costly than on a 'close call' " (Callander and Clark, 2017).
} 
justice to a dispositional majority shifts the final ruling weakly towards that justice's ideal point. Property 3 assures that final rulings cannot be improved for every majority member. Property 4 states that justices have weakly more influence on the final ruling's location in smaller majorities than in larger majorities. ${ }^{9}$

These reduced-form properties for judicial bargaining align with microfounded settings studied elsewhere, including Lax and Cameron (2007), Carrubba and Clark (2012), and Parameswaran, Cameron and Kornhauser (2019). Our approach allows us to take the bargaining equilibria as given and focus on the implications for, and consequences of, case selection.

\section{Analysis}

\section{Dispositional Vote}

We study Subgame Perfect Equilibria in weakly undominated strategies (hereafter just equilibria). In particular, we analyze equilibria featuring 'monotonic' dispositional majorities: either the dispositional vote is unanimous, or there is a justice $i$ such that each justice $j$ votes to move the threshold rightward, $d_{j}=1$, if and only if $j \geq i$. In Lemma B.1 in the appendix, we show that sufficiently strong dispositional motivations ensure that such equilibria exist and henceforth we focus on that case.

In equilibrium, each justice $i$ has a unique cutpoint, $\check{x}_{i}$, fully characterizing her dispositional voting strategy. If $x_{s q}<\check{x}_{i}$, then $i$ votes to shift precedent rightward $\left(d_{i}=1\right)$ and, similarly, $x_{s q} \geq \check{x}_{i}$ implies she votes to shift precedent leftward $\left(d_{i}=0\right)$. Additionally, the cutpoints have the same order as ideal points, which implies monotonic dispositional majorities.

We can use the dispositional cutpoints to easily order final opinions for heard cases as a function of $x_{s q}$. Let $x_{i}^{*}$ denote the final opinion of the dispositional majority if $d_{j}=0$ for all $j \leq i$ and $d_{j}=1$ for all $j>i$. For example, in a five-member court hearing a case with $x_{s q} \in\left(\check{x}_{2}, \check{x}_{3}\right)$, the final opinion $x_{2}^{*}$ is written by justices 3,4 , and 5 . Properties 2 and 4 imply that final opinions are ordered $x_{\frac{n+1}{2}}^{*} \leq x_{\frac{n+1}{2}+1}^{*} \leq \ldots x_{n}^{*}=x_{0}^{*} \leq x_{1}^{*} \leq \cdots \leq x_{\frac{n-1}{2}}^{*}$. Intuitively, the left-leaning bare majority writes the

\footnotetext{
${ }^{9}$ This property can be weakened.
} 
leftmost ruling, $x_{\frac{n+1}{2}}^{*}$, and the right-leaning bare majority writes the rightmost ruling, $x_{\frac{n-1}{2}}^{*} \cdot{ }^{10}$

\section{Case Hearings}

We first establish a necessary condition for a justice to vote to hear a case: she must be in the dispositional majority. In heard cases, the final ruling is worse than $x_{s q}$ for minority justices. Intuitively, they never want to bear costs of hearing cases resulting in worse outcomes.

Lemma 1. Justices never vote to hear a case for which they will be in the dispositional minority.

For case selection with quota $m=\frac{n-1}{2}$, it suffices to focus on two justices who are the decisive pivots, $P_{L}=\frac{n-1}{2}$ and $P_{R}=\frac{n+3}{2}$. We focus on $P_{R}$, as $P_{L}$ is analogous. Optimally hearing a case requires the benefit from setting new precedent to exceed the cost of hearing and deciding the case. Formally, if $x_{s q} \in\left(\check{x}_{i}, \check{x}_{i+1}\right]$ for $i<\frac{n+1}{2}$, then the case is heard if and only if

$$
U_{P_{R}}\left(x_{i}^{*}\right)-c \geq-\left(x_{s q}-\hat{x}_{P_{R}}\right)^{2} .
$$

We can characterize whether the court hears $x_{s q} \leq \check{x}_{\frac{n+1}{2}}$ using conditions similar to (1), and $x_{s q}>\check{x}_{\frac{n+1}{2}}$ using analogous conditions for $P_{L}$.

Lemma 2 shows existence of an interval of cases around $\hat{x}_{\frac{n+1}{2}}$ that are not heard. In the main text, we focus analysis on this interval to emphasize our key points. Yet, there can exist other intervals of non-heard cases. In the appendix, we fully characterize which cases are heard and show that the main analysis illustrates the primary takeaways.

Lemma 2. The court does not hear cases with $x_{s q} \in[\underline{x}, \bar{x}]$, where $\underline{x} \leq \check{x}_{\frac{n+1}{2}} \leq \bar{x}$.

In $[\underline{x}, \bar{x}]$, the left endpoint is the most moderate status quo that the right hearing pivot votes to hear. Similarly, the right endpoint is the most moderate status quo that the left hearing pivot votes to hear. All cases between the endpoints are not heard and their final ruling is $x_{s q}$. See Figure 1(a) for an illustration.

\footnotetext{
${ }^{10}$ Note that $x_{0}^{*}$ and $x_{n}^{*}$ feature equivalent dispositional majorities because they are unanimous.
} 
We are interested in how changing justices' ideal points alters which cases are heard and final rulings. First, we show that more extreme hearing pivots are willing to hear more moderate cases.

Proposition 1. As the right hearing pivot gets more extreme, $\underline{x}$ increases. Symmetrically, $\bar{x}$ decreases as the left hearing pivot gets more extreme.

If a hearing pivot becomes more extreme, two main forces produce Proposition 1. First, status quo on the opposite side of the spectrum become less favorable to the shifting pivot, which encourages granting certiorari. Second, the final ruling can move, which may help or harm the shifting pivot. If it helps her, then this second force complements the first. But if the final ruling becomes less favorable, then the second force discourages granting certiorari and counteracts the first force. Yet, Property 1 implies that the first force always dominates. Thus, the overall effect encourages hearing the case. For example, the overall effect of a more conservative hearing pivot increases $\underline{x}$, so the court hears cases with more moderate liberal precedents.

Although Proposition 1 conveys key forces, it only applies to the central interval of non-heard cases. Proposition 2 extends the result. The key forces are similar.

Proposition 2. As the right hearing pivot gets more extreme, the court hears a broader range of cases with left-leaning precedents. Symmetrically, the court hears a broader range of cases with right-leaning precedents as the left hearing pivot gets more extreme.

\section{Change in Dispositional Majorities}

We have shown that more extreme hearing pivots are willing to hear more moderate cases. Next, we study the effects on (i) the composition of dispositional majorities and (ii) final rulings. In general, more extreme hearing pivots make observed decisions more divisive and final rulings more extreme.

Lemma 2 implies that $\underline{x}$ is the most moderate left-leaning status quo that $P_{R}$ hears. Let

$\hat{x}_{P_{R}}^{\prime} \geq \hat{x}_{P_{R}}$, with corresponding $\underline{x}^{\prime} \geq \underline{x}$, by Proposition 1. Thus, cases $x_{s q} \in\left(\underline{x}, \underline{x}^{\prime}\right)$ are not heard if $\hat{x}_{P_{R}}$ is the right hearing pivot, but are heard if she is replaced by $\hat{x}_{P_{R}}^{\prime}$. For these cases, either the 
Figure 1: Effects of more extreme hearing pivots on case selection and final rulings

(a) Baseline:

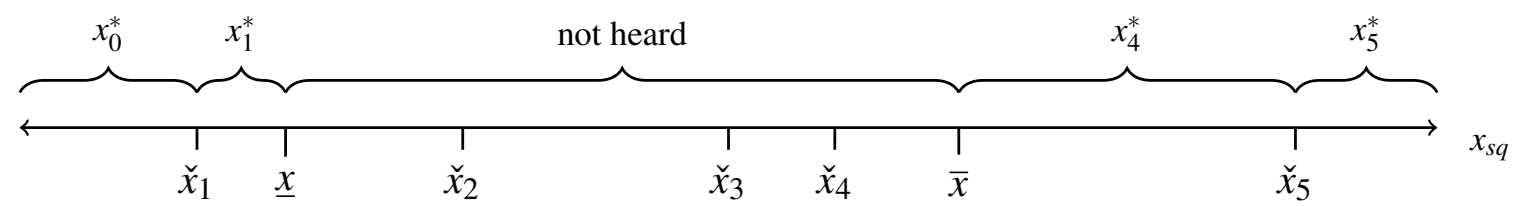

(b) More extreme right hearing pivot, $\hat{x}_{4}^{\prime}>\hat{x}_{4}$ :

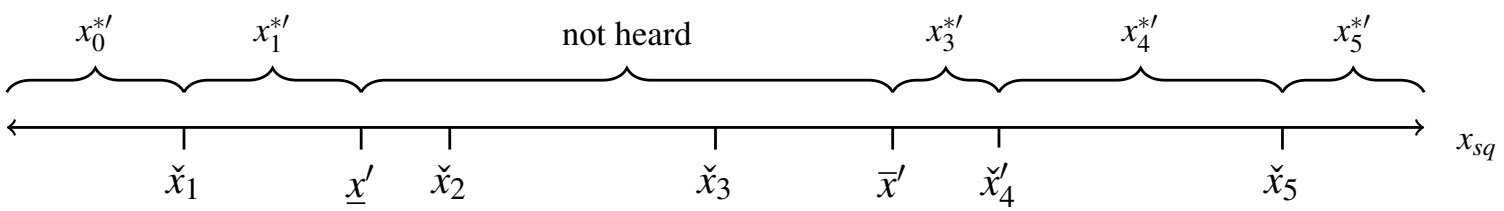

(c) Even more extreme right hearing pivot, $\hat{x}_{4}^{\prime \prime}>\hat{x}_{4}^{\prime}$ :

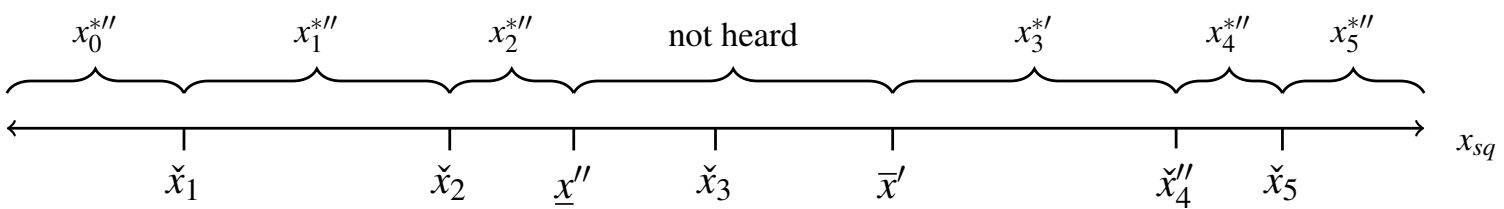

Figure 1(a)-(c) each display a five member court. To ease illustration, each justice $i$ has arbitrarily strong dispositional motivation, so $\hat{x}_{i} \approx \check{x}_{i}$. Curly braces indicate the sets of status quo, $x_{s q}$, mapping to final outcomes, which are not depicted spatially. In (a), final rulings satisfy $x_{4}^{*} \leq x_{5}^{*}=x_{0}^{*} \leq x_{1}^{*}$. In (b), justice 4 shifts rightward to $\hat{x}_{4}^{\prime} \geq \hat{x}_{4}$. The court hears more left-leaning cases, $\underline{x}^{\prime}>\underline{x}$, but the effect on right-leaning cases is ambiguous. A left-leaning bare majority is now possible, if $x_{s q} \in\left(\bar{x}^{\prime}, \breve{x}_{4}^{\prime}\right)$, so the leftmost ruling decreases from (a): $x_{3}^{* \prime}<x_{i}^{*}$ for $i=0,1,4,5$. For each majority also possible in (a), rulings shift right: $x_{i}^{* \prime}>x_{i}^{*}$ for $i=0,1,4,5$. In (c), $\hat{x}_{4}^{\prime \prime} \geq \hat{x}_{4}^{\prime}$. The court hears the same right-leaning cases, $\bar{x}^{\prime \prime}=\bar{x}^{\prime}$, and more left-leaning cases, $\underline{x}^{\prime \prime}>\underline{x}^{\prime}$. The leftmost ruling, $x_{3}^{* \prime}$, is unchanged and rulings shift rightward for each majority also possible in (b). Right-leaning bare majorities are now possible, if $x_{s q} \in\left(\check{x}_{2}, \underline{x}^{\prime \prime}\right)$, so the rightmost ruling increases from (b): $x_{2}^{* \prime \prime}>x_{i}^{* \prime}$ for $i=0,1,3,4,5$.

dispositional majority is identical to that if $x_{s q}=\underline{x}$, or it has fewer justices. Thus, more extreme hearing pivots lead to smaller dispositional majorities for cases with precedent on the opposite side of the spectrum.

More extreme hearing pivots also affect dispositional majorities for cases on their own side. For example, there are cases for which $\hat{x}_{P_{R}}$ joins the dispositional majority but $\hat{x}_{P_{R}}^{\prime}$ joins the minority. This more extreme hearing pivot shrinks the dispositional majority from $\frac{n+1}{2}+1$ to $\frac{n+1}{2}$.

Fixing the court, smaller dispositional majorities produce more extreme final rulings. Thus, changes in dispositional majorities can affect final rulings. For example, some cases will have one 
fewer conservative in their dispositional majorities and, in turn, more liberal final rulings.

\section{Changes in Other Justices}

We now discuss how non-pivotal justices affect case selection. Even though non-pivotal justices are not decisive in case selection, their effect on final rulings can alter $[\underline{x}, \bar{x}]$. If final rulings shift toward a hearing pivot, then the court hears more cases with precedents opposite that pivot. Symmetrically, if final rulings shift away from a hearing pivot, then the court hears fewer cases with precedents opposite that pivot.

For example, a sufficiently extreme justice may pull final rulings farther away from a hearing pivot and expand the interval of non-heard cases. Consider a dispositional majority containing a justice $\hat{x}_{j} \geq \hat{x}_{P_{R}}$ and producing final ruling $x^{*} \geq \hat{x}_{P_{R}}$. If $j$ becomes more extreme, the distance between $\hat{x}_{P_{R}}$ and $x^{*}$ increases by Property 1 . Appointing very extreme justices therefore presents a trade-off: heard cases have more extreme final rulings, but the court may hear fewer cases with moderate precedents.

Moving the court median without changing the overall ordering is roughly equivalent to shifting any other non-hearing-pivot justice. However, the interval characterized in Lemma 2 can shift through changes in dispositional majorities, as well as through changes in final rulings. And if $\underline{x}=\hat{x}_{\frac{n+1}{2}}$, then increasing $\hat{x}_{\frac{n+1}{2}}$ can cause such changes even if the final ruling is unchanged.

If the ordering changes such that a former hearing pivot is now the median justice and a new justice is a hearing pivot, then there are multiple effects. Beyond the already noted effects of moving the hearing pivot, changing the court median switches some cases from one dispositional majority to the other. A new median justice may actually be more important than previously understood because, as far as we are aware, the combined impact on the dispositional majority and case selection has not been noted.

\section{Conclusion}

At the time of writing, the Supreme Court was attracting substantial attention following the death of justice Ruth Bader Ginsberg and subsequent nomination of Amy Coney Barrett. As Barrett 
Figure 2: Effects of other justices on case selection and final rulings

(a) Baseline:

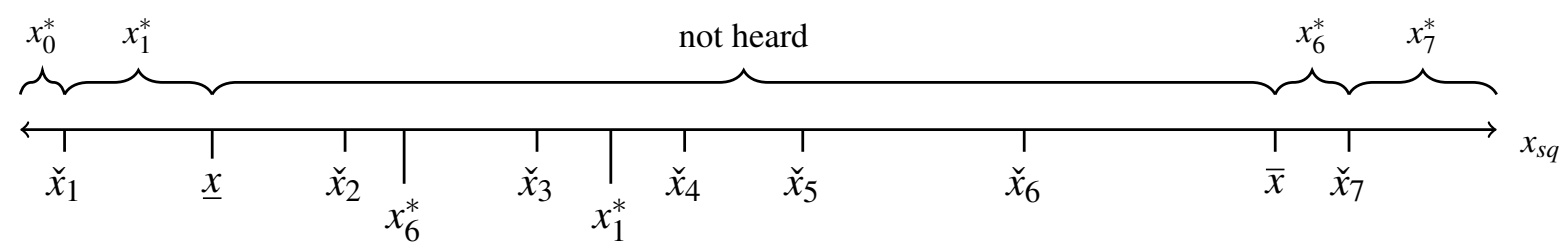

(b) Legislator 6 shifts right, $\hat{x}_{6}^{\prime}>\hat{x}_{6}$ :

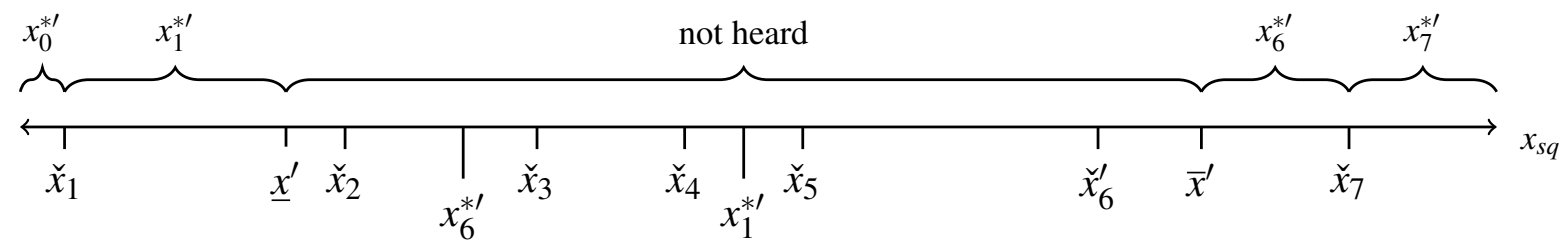

(c) Legislator 7 shifts right, $\hat{x}_{7}^{\prime}>\hat{x}_{7}$ :

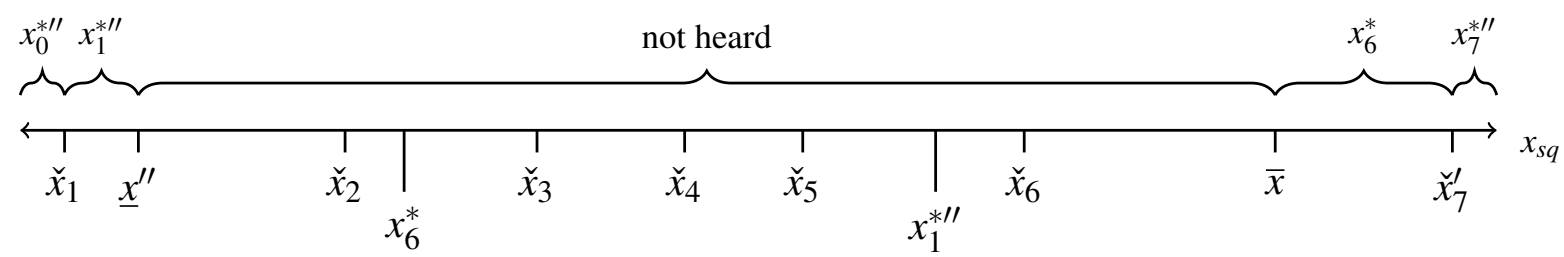

Figure 2 depicts a seven member court. To ease illustration, each justice $i$ has arbitrarily strong dispositional motivation, so $\hat{x}_{i} \approx \check{x}_{i}$. If legislator 6 shifts right from $\hat{x}_{6}$ to $\hat{x}_{6}^{\prime}$, as depicted in (b), then the court hears more cases and the final ruling increases for all heard cases, i.e. $x_{i}^{* \prime}>x_{i}^{*}$ for all $i=0,1,6,7$. If legislator 7 shifts right from $\hat{x}_{7}$ to $\hat{x}_{7}^{\prime}$, as depicted in (c), then the court hears fewer left-leaning cases and the same right-leaning cases. Final rulings weakly increase for all heard cases.

was widely expected to be one of the court's most conservative justices, the median would shift from Roberts to Kavanaugh. This change is clearly important, but our analysis suggests additional significance. Confirming Barrett would not only produce a more conservative median, both hearing pivots would also be more conservative. Roberts would be the new left hearing pivot. Our analysis suggests the new court would hear a broader range of cases with liberal precedents and, with only 3 liberal justices, issue relatively moderate final rulings in cases with "left" majorities.

Following Barrett's nomination, some Democrats discussed "court packing," i.e., adding seats to the Supreme Court. Adding two liberal justices would shift the median leftward. It would also shift both hearing pivots leftward, but how far depends on whether the Rule of Four is modified. 
If the rule changes to reflect additional seats (i.e., a Rule of Five), then the hearing pivots will revert to those before Ginsberg's death (Breyer and Kavanaugh). But maintaining the Rule of Four would produce a left hearing pivot more liberal than Breyer and a right hearing pivot more conservative than Kavanaugh. To match the pre-vacancy court most closely, any expansion must be paired with a modification to the Rule of Four. 


\section{References}

Beim, Deborah. 2017. “Learning in the Judicial Hierarchy.” Journal of Politics 79(2):591-604.

Bonica, Adam, Adam Chilton and Maya Sen. 2020. "The "Odd Party Out" Theory of Certiorari." Available at SSRN 3205620 .

Bryan, Amanda C and Eve M Ringsmuth. 2016. "Jeremiad or Weapon of Words?: The Power of Emotive Language in Supreme Court Dissents.” Journal of Law and Courts 4(1):159-185.

Buchanan, Larry and Karen Yourish. 2018. “After Kennedy’s Exit, Supreme Court's Center Is Likely to Shift Right.” The New York Times .

URL: $\quad$ https://www.nytimes.com/interactive/2018/06/27/us/politics/supreme-court-movesright.html

Callander, Steven and Tom S. Clark. 2017. "Precedent and Doctrine in a Complicated World." American Political Science Review 111(1):184-203.

Cameron, Charles M. and Jonathan P. Kastellec. 2016. “Are Supreme Court Nominations a Movethe-Median Game?” American Political Science Review 110(4):778-797.

Cameron, Charles M and Lewis A Kornhauser. 2010. "Modeling collegial courts (3): Adjudication equilibria.” NYU School of Law, Public Law Research Paper (09-39):09-29.

Cameron, Charles M. and Lewis A. Kornhauser. 2017. “Theorizing the US Supreme Court.” Oxford Research Encyclopedia of Politics .

Carrubba, Clifford J., Barry Friedman, Andrew D. Martin and Georg Vanberg. 2012. "Who Controls the Content of Supreme Court Opinions?” American Journal of Political Science 56(2):400-412.

Carrubba, Clifford J. and Tom S. Clark. 2012. "Rule Creation in a Political Hierarchy." American Political Science Review 106(3):622-643. 
Clark, Tom S. and Jonathan P. Kastellec. 2013. "The Supreme Court and Percolation in the Lower Courts: An Optimal Stopping Model.” Journal of Politics 75(1):150-168.

Fang, Songying, Timothy R Johnson and Jason M Roberts. 2007. "Will of the Minority: Rule of Four on the United States Supreme Court.” Available at SSRN 998492.

Fox, Justin and Georg Vanberg. 2014. "Narrow Versus Broad Judicial Decisions.” Journal of Theoretical Politics 26(3):355-383.

Ginsburg, Ruth Bader. 2010. “The Role of Dissenting Opinions.” Minnesota Law Review 95:1.

Johnson, Benjamin. 2018. “The Supreme Court's Political Docket: How Ideology and the Chief Justice Control the Court's Agenda and Shape Law." Conn. L. Rev. 50:581.

Kastellec, John P. 2017. “The Judicial Hierarchy.” Oxford Research Encyclopedia of Politics .

Kastellec, Jonathan P. and Jeffrey R. Lax. 2008. "Case Selection and The Study of Judicial Politics." Journal of Empirical Legal Studies 5(3):407-446.

Krehbiel, Keith. 2007. "Supreme Court appointments as a move-the-median game.” American Journal of Political Science 51(2):231-240.

Lax, Jeffrey R. 2003. "Certiorari and Compliance in the Judicial Hierarchy: Discretion, Reputation and the Rule of Four." Journal of Theoretical Politics 15(1):61-86.

Lax, Jeffrey R. and Charles M. Cameron. 2007. "Bargaining and Opinion Assignment on the US Supreme Court.” The Journal of Law, Economics, \& Organization 23(2):276-302.

Moraski, Bryon J and Charles R Shipan. 1999. "The politics of Supreme Court nominations: A theory of institutional constraints and choices.” American Journal of Political Science pp. 10691095.

Parameswaran, Giri. 2018. "Endogenous Cases and the Evolution of the Common Law." The RAND Journal of Economics 49(4):791-818. 
Parameswaran, Giri, Charles M. Cameron and Lewis A. Kornhauser. 2019. "Bargaining and Strategic Voting on Appellate Courts.” Available at SSRN 3397299.

Roeder, Oliver. 2018. “John Roberts Has Cast A Pivotal Liberal Vote Only 5 Times.” FiveThirtyEight .

URL: https://fivethirtyeight.com/features/john-roberts-has-cast-a-pivotal-liberal-vote-only-5times/ 


\section{A Comparison with Majority Rule for Case Hearings}

Before proving our main results, we compare Rule of Four to case selection via majority rule, where the median justice is the sole hearing pivot.

Proposition 3. The court hears a smaller set of cases under majority rule than under Rule of Four

Proof. First, dispositional votes do not depend on the case selection rule. Second, judges use weakly undominated voting strategies for case selection. Thus, case selection strategies does not depend on the rule in the equilibria we study. Increasing the quota requirement for case selection therefore cannot expand the set of heard cases.

Changing the Rule of Four to majority rule would not change the final rulings of heard cases, which are determined collectively by the dispositional majority regardless. But the court would be less willing to hear moderate cases. Whether this is improves social welfare depends on how closely the median justice aligns with citizen preferences.

\section{B Proofs}

Recall that $x_{i}^{*}$ denotes the final ruling's location if $d_{j}=0$ for all $j \leq i$ and $d_{j}=1$ for all $j>i$.

Lemma B.1. If dispositional motivation is sufficiently strong, then the dispositional voting subgame has a PSNE with monotonic dispositional majorities in which $d_{i}=1$ if and only if $x_{s q} \leq \check{x}_{i}$, where: $\hat{x}_{i} \leq \check{x}_{i}$ for all $i<\frac{n+1}{2}$, and $\hat{x}_{i} \geq \check{x}_{i}$ for all $i>\frac{n+1}{2}$.

Proof. First, we define $\check{x}_{i}$ for $i \leq \frac{n+1}{2}$. Let $x_{i}^{\prime}$ be the unique $x_{s q} \geq \hat{x}_{i}$ solving $u_{i}\left(x_{i}^{*}\right)=u_{i}\left(x_{i-1}^{*}\right)+$ $l\left(x_{s q}-\hat{x}_{i}\right)$, and similarly let $x_{i}^{\prime \prime}$ be the unique $x_{s q} \geq \hat{x}_{i}$ solving $u_{i}\left(x_{i}^{*}\right)=u_{i}\left(x_{s q}\right)+l\left(x_{s q}-\hat{x}_{i}\right)$. Note that $x_{i}^{\prime}=x_{i}^{\prime \prime}$ if $x_{i}^{\prime}=x_{i-1}^{*}$, and $x_{i}^{\prime \prime} \leq x_{i-1}^{*}$ if $x_{i}^{\prime} \leq x_{i-1}^{*}$. Define

$$
\check{x}_{i}= \begin{cases}x_{i}^{\prime} & \text { if } x_{i}^{\prime} \leq x_{i-1}^{*} \\ x_{i}^{\prime \prime} & \text { else. }\end{cases}
$$


For $i>\frac{n+1}{2}$, define $\check{x}_{i}$ in a symmetric way. If dispositional motivation is sufficiently strong, i.e., $l$ decreases fast enough as $x_{s q}$ shifts away from $\hat{x}_{i}$, then: $\check{x}_{i} \in\left[\hat{x}_{i}, \hat{x}_{i+1}\right)$ for $i<\frac{n+1}{2}, \check{x}_{i} \in\left(\hat{x}_{i-1}, \hat{x}_{i}\right]$ for $i>\frac{n+1}{2}$, and $\check{x}_{\frac{n+1}{2}}<\check{x}_{P_{R}}$. Thus, $\check{x}_{i} \leq \check{x}_{i+1}$ for all $i$.

Construct a profile of dispositional voting strategies such that $d_{i}=1$ if and only if $x_{s q}<\check{x}_{i}$. In this profile, dispositional majorities are always monotonic because $\check{x}_{i} \leq \check{x}_{i+1}$ for all $i$.

It remains to check that no justice has a profitable deviation. Consider justice $j \leq \frac{n+1}{2}$, as symmetric arguments apply to $j>\frac{n+1}{2}$. First, suppose $x_{s q} \leq \hat{x}_{j}$. Voting 0 is not a profitable deviation because $d_{j}=1$ matches $j$ 's dispositional motivation and also includes her in the dispositional majority, which shifts the ruling towards $\hat{x}_{j}$ by Property 2 . Second, suppose $x_{s q} \in\left(\hat{x}_{j}, \min \left\{x_{j-1}^{*}, \hat{x}_{j+1}\right\}\right)$. Then $j$ strictly prefers voting 0 iff $u_{j}\left(x_{j}^{*}\right)>u_{j}\left(x_{j-1}^{*}\right)+l\left(x_{s q}-\hat{x}_{j}\right)$, which is equivalent to $x_{s q}>x_{j}^{\prime}$. Next, suppose $x_{s q} \in\left(\max \left\{\hat{x}_{j}, x_{j-1}^{*}\right\}, \hat{x}_{j+1}\right)$. Then $j$ strictly prefers voting 0 iff $u_{j}\left(x_{j}^{*}\right)>u_{j}\left(x_{s q}\right)+$ $l\left(x_{s q}-\hat{x}_{j}\right)$, equivalently $x_{s q}>x_{j}^{\prime \prime}$. By properties of $x_{j}^{\prime \prime}$ and $x_{j}^{\prime}$, the previous two cases imply that $j$ strictly prefers voting 0 for $x_{s q} \in\left(\hat{x}_{j}, \hat{x}_{j+1}\right)$ iff $x_{s q}>\check{x}_{j}$. Finally, suppose $x_{s q}>\hat{x}_{j+1}$. If $l\left(\hat{x}_{j+1}-\hat{x}_{j}\right)$ is sufficiently negative, then voting 1 is not a profitable deviation.

Henceforth, we assume dispositional motivation is strong enough to apply Lemma B.1.

Proof of Lemma 1. In the PSNE of the dispositional voting subgame characterized in Lemma B.1, the final ruling is worse than $x_{s q}$ for each minority justice. Thus, it is never strictly optimal for any justice to support hearing a case if she will be in the dispositional minority, as she would incur cost $c \geq 0$ to get an inferior final ruling.

Proof of Lemma 2. Set $\check{x}_{0}=-\infty$ and fix $i \in\left\{0,1, \ldots, \frac{n-1}{2}\right\}$. Consider $x_{s q} \in\left(\check{x}_{i}, \check{x}_{i+1}\right]$. If $x_{s q} \in$ $\left[x_{i}^{*}, \check{x}_{i+1}\right)$, then the case is heard iff $U_{P_{R}}\left(x_{s q}\right)-c \leq u_{P_{R}}\left(x_{s q}\right)$. Otherwise, the case is heard iff $U_{P_{R}}\left(x_{i}^{*}\right)-$ $c \geq u_{P_{R}}\left(x_{s q}\right)$, which is equivalent to $x_{s q} \leq \tilde{x}_{i} \equiv \hat{x}_{P_{R}}-\sqrt{c+\left(x_{i}^{*}-\hat{x}_{P_{R}}\right)^{2}}$ because $\hat{x}_{P_{R}} \geq \check{x}_{i+1}$ by Lemma B.1. Note that $\tilde{x}_{i}<x_{i}^{*}$ if $x_{i}^{*} \leq \check{x}_{i+1}$. Define $\underline{x}_{i}=\max \left\{\check{x}_{i}, \min \left\{\check{x}_{i+1}, \tilde{x}_{i}\right\}\right\}$.

Next, set $\hat{x}_{n+1}=\infty$. For $i \in\left\{\frac{n+1}{2}, \ldots, n+1\right\}$, we can symmetrically define $\tilde{x}_{i}=\hat{x}_{P_{L}}+$ $\sqrt{c+\left(x_{i}^{*}-\hat{x}_{P_{L}}\right)^{2}}$ and $\bar{x}_{i}=\min \left\{\check{x}_{i}, \max \left\{\check{x}_{i-1}, \tilde{x}_{i}\right\}\right\}$. Also symmetric to the preceding case, $\tilde{x}_{i}>x_{i}^{*}$ if $x_{i}^{*} \geq \check{x}_{i}$. 
Setting $\underline{x}=\max \left\{\underline{x}_{i} \mid \underline{x}_{i}>\check{x}_{i}\right\}$ and $\bar{x}=\min \left\{\bar{x}_{i} \mid \bar{x}_{i}<\check{x}_{i}\right\}$, the case is not heard if $x_{s q} \in[\underline{x}, \bar{x}]$.

Proposition 1. If $\hat{x}_{P_{R}}$ increases to $\hat{x}_{P_{R}}^{\prime}$, then $\underline{x} \leq \underline{x}^{\prime}$. Similarly, if $\hat{x}_{P_{L}}$ decreases to $\hat{x}_{P_{L}}^{\prime}$, then $\bar{x}^{\prime} \leq \bar{x}$.

Proof. By Lemma 2, we have $\underline{x} \in\left\{\hat{x}_{P_{R}}-\sqrt{c+\left(x_{i}^{*}-\hat{x}_{P_{R}}\right)^{2}}, \check{x}_{i+1}\right\}$ for some $i<\frac{n+1}{2}$. We show $\frac{\partial \underline{x}}{\partial \hat{x}_{P_{R}}} \geq$ 0 . Analogous arguments imply $\bar{x}$ decreases as $\hat{x}_{P_{L}}$ shifts leftward.

Case 1. Suppose $\underline{x}=\hat{x}_{P_{R}}-\sqrt{c+\left(x_{i}^{*}-\hat{x}_{P_{R}}\right)^{2}}$. There are two possible subcases: $x_{i}^{*} \leq \hat{x}_{P_{R}}$ and $x_{i}^{*}>\hat{x}_{P_{R}}$

First, if $x_{i}^{*} \leq \hat{x}_{P_{R}}$, then

$$
\begin{aligned}
\frac{\partial \underline{x}}{\partial \hat{x}_{P_{R}}} & =1+\frac{x_{i}^{*}-\hat{x}_{P_{R}}}{\sqrt{c+\left(x_{i}^{*}-\hat{x}_{P_{R}}\right)^{2}}}\left(1-\frac{\partial x_{i}^{*}}{\partial \hat{x}_{P_{R}}}\right) \\
& =1+\frac{\hat{x}_{P_{R}}-x_{i}^{*}}{\sqrt{c+\left(x_{i}^{*}-\hat{x}_{P_{R}}\right)^{2}}}\left(\frac{\partial x_{i}^{*}}{\partial \hat{x}_{P_{R}}}-1\right) \\
& \geq 1-\frac{\hat{x}_{P_{R}}-x_{i}^{*}}{\sqrt{c+\left(x_{i}^{*}-\hat{x}_{P_{R}}\right)^{2}}} \\
& \geq 0,
\end{aligned}
$$

where (3) follows from Property 1 and $x_{i}^{*} \leq \hat{x}_{P_{R}}$, and (4) because $c \geq 0$ implies $\sqrt{c+\left(x_{i}^{*}-\hat{x}_{P_{R}}\right)^{2}} \geq$ $\hat{x}_{P_{R}}-x_{i}^{*}$.

$$
\text { For } x_{i}^{*}>\hat{x}_{P_{R}} \text {, }
$$

$$
\begin{aligned}
\frac{\partial \underline{x}}{\partial \hat{x}_{R}} & =1+\frac{x_{i}^{*}-\hat{x}_{P_{R}}}{\sqrt{c+\left(x_{i}^{*}-\hat{x}_{P_{R}}\right)^{2}}}\left(1-\frac{\partial x_{i}^{*}}{\partial \hat{x}_{P_{R}}}\right) \\
& \geq \frac{x_{i}^{*}-\hat{x}_{P_{R}}}{\sqrt{c+\left(x_{i}^{*}-\hat{x}_{P_{R}}\right)^{2}}}\left(1-\frac{\partial x_{i}^{*}}{\partial \hat{x}_{P_{R}}}\right) \\
& \geq 0
\end{aligned}
$$

where (6) follows from (5) by Property 1.

Case 2. Suppose $\underline{x}=\check{x}_{i+1}$. Then $\underline{x} \geq \hat{x}_{i+1}$ and satisfies $u_{i+1}\left(x_{i+1}^{*}\right)=u_{i+1}\left(x_{i}^{*}\right)+l\left(\underline{x}-\hat{x}_{i+1}\right)$. 
Applying the implicit function theorem,

$$
\begin{aligned}
\frac{\partial \underline{x}}{\partial \hat{x}_{P_{R}}} & =\left(\frac{\partial u_{i+1}\left(x_{i+1}^{*}\right)}{\partial x_{i+1}^{*}} \frac{\partial x_{i+1}^{*}}{\partial \hat{x}_{P_{R}}}-\frac{\partial u_{i+1}\left(x_{i}^{*}\right)}{\partial x_{i}^{*}} \frac{\partial x_{i}^{*}}{\partial \hat{x}_{P_{R}}}\right)\left(\frac{\partial l\left(\underline{x}-\hat{x}_{i+1}\right)}{\partial \underline{x}}\right)^{-1} \\
& \propto \frac{\partial u_{i+1}\left(x_{i}^{*}\right)}{\partial x_{i}^{*}} \frac{\partial x_{i}^{*}}{\partial \hat{x}_{P_{R}}}-\frac{\partial u_{i}\left(x_{i+1}^{*}\right)}{\partial x_{i+1}^{*}} \frac{\partial x_{i+1}^{*}}{\partial \hat{x}_{P_{R}}}
\end{aligned}
$$

Thus, $\frac{\partial \underline{x}}{\partial \hat{x}_{R}} \geq 0$ iff

$$
\frac{\partial u_{i+1}\left(x_{i}^{*}\right)}{\partial x_{i}^{*}} \frac{\partial x_{i}^{*}}{\partial \hat{x}_{P_{R}}} \geq \frac{\partial u_{i}\left(x_{i+1}^{*}\right)}{\partial x_{i+1}^{*}} \frac{\partial x_{i+1}^{*}}{\partial \hat{x}_{P_{R}}} .
$$

If $\frac{\partial x_{i}^{*}}{\partial \hat{x}_{P_{R}}}=0$, then (9) holds because $\hat{x}_{i+1}<x_{i+1}^{*}$ by Property 3, so $\frac{\partial u_{i+1}\left(x_{i+1}^{*}\right)}{\partial x_{i+1}^{*}}<0$. If $\frac{\partial x_{i}^{*}}{\partial \hat{x}_{P_{R}}}>0$, then (9) is equivalent to

$$
\frac{\frac{\partial u_{i+1}\left(x_{i}^{*}\right)}{\partial x_{i}^{*}}}{\frac{\partial u_{i+1}\left(x_{i+1}^{*}\right)}{\partial x_{i+1}^{*}}} \leq \frac{\frac{\partial x_{i+1}^{*}}{\partial \hat{x}_{R}}}{\frac{\partial x_{i}^{*}}{\partial \hat{x}_{R}}}
$$

The LHS of (10) is in $[0,1]$ because $\hat{x}_{i+1} \leq x_{i}^{*} \leq x_{i+1}^{*}$ with at least one strict inequality, and the RHS is greater than or equal to 1 by Properties 1 and 4. Thus, (10) holds.

The interval $[\underline{x}, \bar{x}]$ studied in Proposition 1 does not always fully characterize the set of heard cases. We now fully characterize this set, extend Proposition 1, and prove Proposition 3.

The proof of Lemma 2 implies that the non-heard set is

$$
\mathscr{G}=\left\{\cup_{i<\frac{n+1}{2}}\left[\underline{x}_{i}, \check{x}_{i+1}\right]\right\} \cup\left\{\cup_{i>\frac{n+1}{2}}\left[\check{x}_{i-1}, \bar{x}_{i}\right]\right\}
$$

and $[\underline{x}, \bar{x}] \subseteq \mathscr{G}$. In general, $\mathscr{G}$ may also contain intervals of unheard cases disjoint from $[\underline{x}, \bar{x}]$. With sufficiently strong dispositional motivation, we prove a more general version of Proposition 1 .

Proof of Proposition 2. Without loss of generality, suppose $\hat{x}_{P_{R}}$ increases. If $\mathscr{G}=[\underline{x}, \bar{x}]$, then Proposition 1 yields the result. Suppose $\mathscr{G}$ contains at least one interval $\left[\underline{x}^{\prime}, \bar{x}^{\prime}\right]$ disjoint from $[\underline{x}, \bar{x}]$, with $\bar{x}^{\prime}<\underline{x}$. 
The characterization for $\mathscr{G}$ in (11) implies $\bar{x}^{\prime}=\check{x}_{i}$ for some $i<\frac{n+1}{2}$. Analogous to (7), applying the implicit function theorem yields $\frac{\partial \bar{x}^{\prime}}{\partial \hat{x}_{P_{R}}}=\left(\frac{\partial u_{i}\left(x_{i+1}^{*}\right)}{\partial x_{i+1}^{*}} \frac{\partial x_{i+1}^{*}}{\partial \hat{x}_{P_{R}}}-\frac{\partial u_{i}\left(x_{i}^{*}\right)}{\partial x_{i}^{*}} \frac{\partial x_{i}^{*}}{\partial \hat{x}_{P_{R}}}\right)\left(\frac{\partial l\left(\underline{x}-\hat{x}_{i}\right)}{\partial \underline{x}}\right)^{-1}$. It follows that $\frac{\partial \bar{x}^{\prime}}{\partial \hat{x}_{P_{R}}}$ goes to zero as $\left|\frac{\partial l\left(\underline{x}-\hat{x}_{i}\right)}{\partial \underline{x}}\right|$ gets large.

Next, we claim $\underline{x}^{\prime}=\tilde{x}_{j}$ for some $j \leq i-1$. By Case 1 in the proof of Proposition 1, proving this claim implies that $\underline{x}^{\prime}$ shifts inward. To show the claim, we proceed by contradiction. Suppose $\underline{x}^{\prime}=\check{x}_{j}$ for some $j<i-1$. This requires $\tilde{x}_{j} \leq \check{x}_{j} \leq \tilde{x}_{j-1}$. Properties 2 and 3 imply $x_{i^{\prime}}^{*}$ increases monotonically over $i^{\prime} \leq \frac{n+1}{2}$. Thus, $\tilde{x}_{j} \leq \tilde{x}_{j-1}$ implies $\tilde{x}_{k+1} \leq \tilde{x}_{k}$ for all $k \in\left\{j, \ldots, \frac{n-1}{2}\right\}$. But then we must have a contradiction: $\tilde{x}_{i} \leq \tilde{x}_{j} \leq \check{x}_{j} \leq \check{x}_{i}<\tilde{x}_{i}$, where the strict inequality follows because $\check{x}_{i}=\bar{x}^{\prime}<\underline{x}$ implies $\check{x}_{i}<\underline{x}_{i}$, and thus $\check{x}_{i}<\tilde{x}_{i}$.

We have shown that $\underline{x}$ and $\underline{x}^{\prime}$ shift inward, and the effect on $\bar{x}^{\prime}$ vanishes as $\left|\frac{\partial l\left(\underline{x}-\hat{x}_{i}\right)}{\partial \underline{x}}\right|$ gets large. Because analogous arguments apply to any interval of policies disjoint from $[\underline{x}, \bar{x}]$, sufficiently strong dispositional motivations yield the desired result. 